\title{
Development of a novel user-friendly platform to couple light regime characterization with particle tracking - cells' light history determination during phototrophic cultivations
}

\author{
Bruno D. Fernandes ${ }^{a}{ }^{*}$, André Mota ${ }^{a}$, Pedro Geada ${ }^{a}$, João L. Oliveira ${ }^{a}$, José A. Teixeira ${ }^{a}$, \\ Vítor Vasconcelos ${ }^{\mathrm{b}}$, António A. Vicente ${ }^{\mathrm{a}}$ \\ a CEB-Centre of Biological Engineering, University of Minho, Braga, Portugal \\ b CIIMAR/CIMAR - Interdisciplinary Centre of Marine and Environmental Research, Department of Biology, Faculty of Sciences, University Porto, Porto, Portugal
}

\section{A R T I C L E I N F O}

\section{Keywords:}

Microalgae

Cyanobacteria

Photobioreactor

Cells' light history

Hydrodynamics

\begin{abstract}
A B S T R A C T
Depending on the light regime inside the photobioreactor (PBR) and the flow pattern verified, cells experience different histories with respect to the light regimes they are exposed to, wavelengths of light absorbed and period of time spent under each specific condition. The high heterogeneity of the radiation field inside the PBR - due to absorption and scattering of radiation by microalgae/cyanobacteria cells - and the fluctuating cells' light history (CLH), greatly influence photosynthetic conversion and ultimately biomass productivity.

This work presents a relatively low-cost, simple, experimental technique which combines light regime and flow pattern characterization, to determine the CLH inside PBRs. A fibre optic spectrometer and probes were employed for quantitative and qualitative light characterization/mapping inside the PBR - in this study a split cylinder airlift photobioreactor (SCAPBR) was used - while the flow pattern was determined by means of two perpendicular digital cameras which were used to follow fluorescent alginate particles.

Temporal and spatial aspects of light patterns were obtained using a MATLAB algorithm that enables automatic merging and synchronization of the data obtained by those two approaches. This provided information about the average time during which cells are subjected to each light regime and how they alternate between them, thus characterizing their CLH.
\end{abstract}

\section{Introduction}

One of the most important and challenging topics in phototrophic cultivation of microalgae and cyanobacteria is associated with the optimization of biomass productivity and, consequently, its cost-effectiveness. In order to optimize the cultivation system productivity, the balance between different factors such as light supply, reactor hydrodynamics and mass transfer must be considered.

Qualitative (wavelengths) and quantitative (intensity) light characterization inside the photobioreactor (PBR) is of utmost importance since microalgae and cyanobacteria growth and metabolite production are influenced by light intensity and their ability to use the photons' energy, which depends on the wavelength of radiation [1]. Additionally, turbulent flow conditions and light gradients frequently occur together in PBRs. Thus, photosynthetic cells cultivated in such reactors experience light intensity fluctuations that vary in extent and frequency, being highly dependent on hydrodynamic conditions and PBR geometry $[1,2]$.
It is also known that the conversion of light energy to biomass can be enhanced if cells are forced to repeatedly cycle between the light and dark areas of the PBR. This is achieved when ordered mixing forces the cells to experience periodical light/dark cycles. The effect of these cycles has been extensively studied [3-5], and it was found that periodical light/dark cycles provided by a regular and defined pattern flow [6], offered for example by airlift PBRs, might enhance growth $[2,7]$ in opposition to random mixing. Several authors have shown that light patterns influence microalgal growth and product formation [3,5,8-10]. In addition light intensity and duration of light-dark (LD) intervals are also very relevant parameters [11].

These studies reveal how crucial is the determination and manipulation of cells' light history (CLH) as a strategy to optimize biomass productivity. However, to determine and then control the CLH, it is necessary to know and integrate the light regime characterization (light characterization in each PBR point) with the cells' flow pattern inside de PBR.

\footnotetext{
* Corresponding author.

E-mail address: brunofernandes@deb.uminho.pt (B.D. Fernandes).
} 


\subsection{Determination of light distribution inside PBRs}

Different options to obtain light characterization inside PBRs can be found in the literature but generally they use a similar approach, which is based on theoretical models [12-17]. For the construction of an accurate model, both light absorption and scattering by pigments and cells, respectively, have to be considered [18] [19] developed a twoflux formulation based on a one-dimensional light attenuation hypothesis and assuming both a quasi-collimated field of radiation and a normal light incidence. This model was subsequently used by different authors $[20,21]$. A methodology where a spherical quantum sensor is used to obtain the incident light flux (in an empty PBR) is described by [20]. The results obtained through this methodology were then used as initial conditions in the light transfer modeling.

Most of light characterizations described on the literature are based on the one-dimensional hypothesis i.e., light attenuation occurs in a unique main direction, perpendicular to the illuminated face of the PBR [12,22-26] as evidenced by the list presented by [27]. Additionally, to simplify calculations, the models generally do not consider the wavelength in the determination of light distribution [21]. The utilization of models for light characterization, especially in more complex geometries, can be complex and time-consuming [21,27].

\subsection{Determination of cell flow pattern}

Regarding the determination of cell trajectory inside bioreactors, there are two main approaches described in the literature: 1) experimental measurement using particle tracking or 2) Computational Fluid Dynamics (CFDs).

Some of the most common experimental measurement techniques include Particle Image Velocimetry (PIV) [20], Laser Doppler Velocimetry (LDV) [28], and Radioactive Tracking Particle (RTP) [29], which can be computed automatically (CARTP) $[30,31]$. These techniques can also be used to validate results obtained by CFDs calculations [32-39]. The main limitations of all these techniques used for determination of cell trajectory are the price, complexity and, when models and CFDs are used, the need for complementary experimental techniques in order to validate the results. These techniques often analyse sections and not the PBR as a whole. This means that several experiments are needed in order to measure the cell flow pattern in all PBR sections, being the trajectories based on statistical data and not on the real trajectory of the main particles. Given those limitations, it is important to have a method that allows measuring the cell flow patterns in the complete volume of PBRs, being the statistical data retrieved from the global trajectory.

\subsection{Determination of cells' light history}

In order to automatically determine the CLH, it is necessary to merge and integrate data from light characterization and cells' flow pattern obtained from different techniques, which can be a very challenging and complex task due to the different nature of outputs available. The ability to merge the results from both studies is thus of extreme importance in order to be able to describe properly the light history of a single photosynthetic cell [1] and therefore, determinate the CLH of the whole culture.

Although there are several techniques for the characterization of light distribution and determination of flow patterns inside the PBR, to our knowledge there is no technique available to integrate these two characteristics in order to determine the time that cells spend in each light regime and the frequency of light/dark cycles that cells are exposed to; further, it would be advantageous if that could be done automatically, using low-cost equipment, and in a simple way.

Therefore, in this work we propose a user-friendly platform to couple light regime characterization with particle tracking in order to evaluate the CLH inside PBRs (Fig. 1). This technique allows a full light characterization based on experimental results obtained with optical

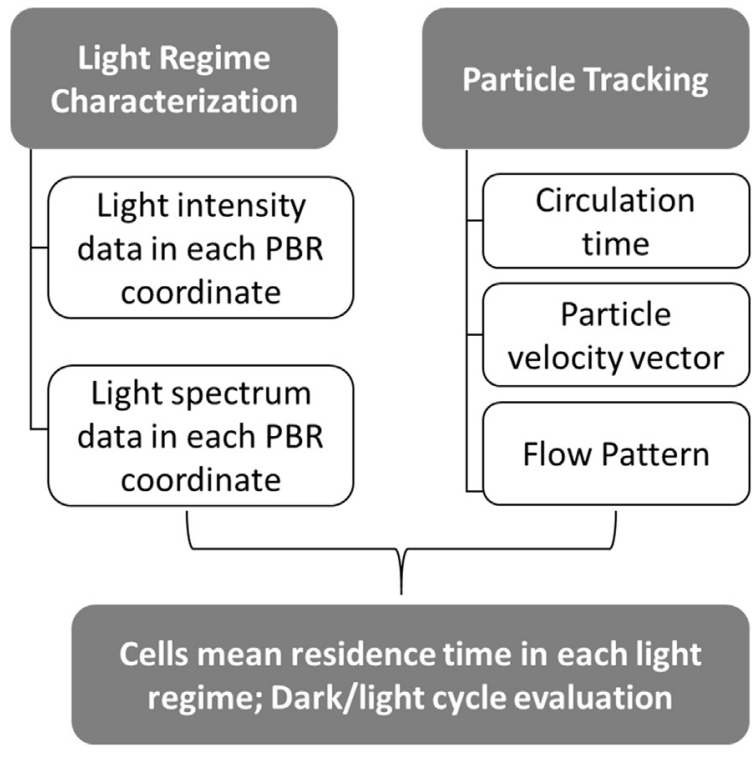

Fig. 1. Technical approach for CLH determination.

fibre technology, which provide accurate and precise information regarding quantitative (photosynthetic photon flux density) and qualitative (spectral intensity distribution) aspects of light patterns in each point of the PBR [1].

The cell trajectory is determined using optical detection of a single fluorescent particle that is followed by a set of two synchronized video cameras. The results obtained with these two techniques are then integrated and combined in order to obtain the CLH or "temporal irradiance pattern" (Fig. 1). Other hydrodynamic parameters such as liquid velocity, circulation time and Reynolds number can also be estimated using the outputs of this technique.

For exemplification purposes and in order to demonstrate the technique's fundamentals, outputs and potentialities, a split cylinder airlift PBR (SCAPBR) previously described elsewhere [2] will be used as case-study. The main steps, from light regime characterization to flow pattern determination (using optical fibre technology and image analysis, respectively) and the process of merging/synchronization of data in order to obtain the CLH will be presented and explained through illustrative results obtained by the utilization of this technique in the SCAPBR characterization.

\section{Procedure for cells' light history determination - SCAPBR case study}

A split cylinder airlift photobioreactor (SCAPBR) was used to test this new technique for CLH determination (Fig. 2). Both the light regime characterization and flow pattern determination were done in the SCAPBR 50, being the first performed in the presence of different concentrations of Chlorella vulgaris $\mathrm{P} 12$ and the second in the absence of cells. This SCAPBR 50 - previously described and hydrodynamically characterized elsewhere [2] - is made of $3.8 \mathrm{~mm}$ thick, transparent poly (methyl methacrylate) with $90 \mathrm{~mm}$ of internal diameter. The liquid height was $600 \mathrm{~mm}$ (total height $700 \mathrm{~mm}$ ) and the working volume was 3.7 L, with a riser/downcomer ratio of 1.0 (riser is represented in Fig. 2 by a upward arrow while the downcomer by a downward arrow). The baffle, also made of transparent poly(methyl methacrylate) to allow light penetration, is $4.0 \mathrm{~mm}$ thick and is positioned $50 \mathrm{~mm}$ from the bottom of the reactor and up to $50 \mathrm{~mm}$ below the liquid level.

The culture was mixed by sparging air through a sparger composed by nineteen needles uniformly spaced. The needles, with $0.25 \mathrm{~mm}$ of diameter $\left(d_{n}\right)$ and $20 \mathrm{~mm}$ length $\left(L_{n}\right)$, had $5.0 \mathrm{~mm}$ of distance between them. The shape and size of the needles ensure the formation of small and well-defined bubbles. Needles' placement enables a uniform bubble 


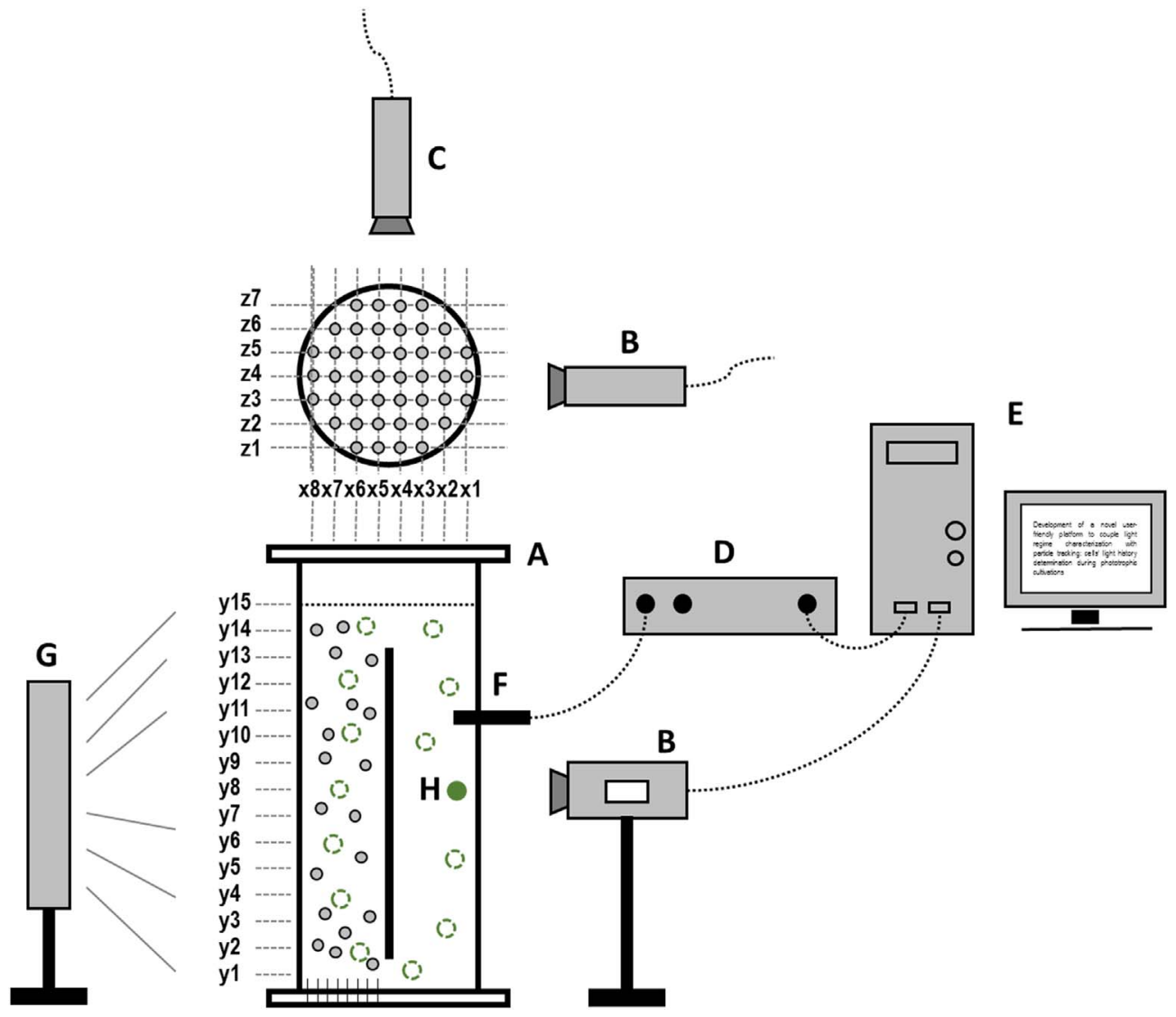

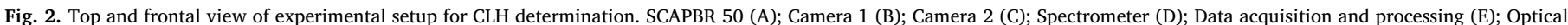

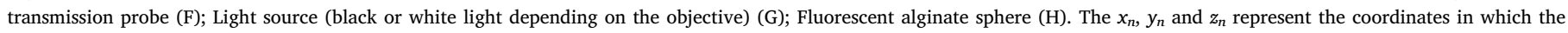
SCAPBR was subdivided for data processing purposes and the grey circles in top view represent the sample points for light characterization.
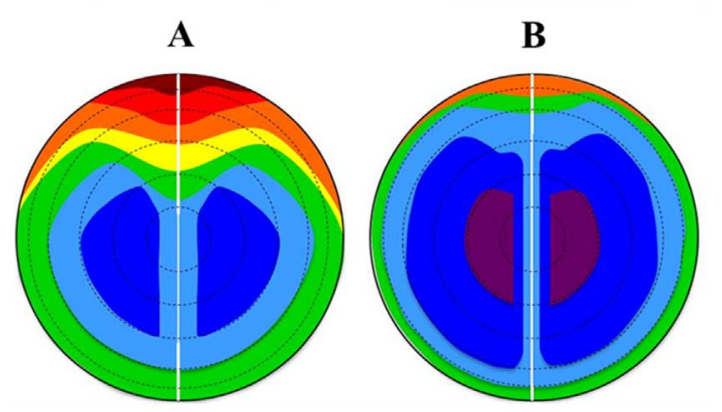

L. I. $\left(\mu \mathrm{E} \mathrm{m}^{2} \mathrm{~s}^{-1}\right)$ $\left(\mu \mathrm{E} \mathbf{m}^{2} \mathbf{s}^{-1}\right)$ 234.8 196.5 177.4 158.2 139.1
119.9 119.9
100.8 81.62 62.46 43.31 24.15 24.15
5.000

Fig. 3. Illustrative light intensity profiles (top view) inside the SCAPBR obtained at different $C$. vulgaris cell concentrations of $0.25 \mathrm{~g} \mathrm{~L}^{-1}$ (A) and $1.0 \mathrm{~g} \mathrm{~L}^{-1}$ (B).

distribution along the PBR.

The cells of Chlorella vulgaris P12 used during this work were grown under the conditions described by [2] and placed in the SCAPBR for light regime characterization. Flow pattern determination was done in the absence of cells.

\subsection{Light regime characterization}

The SCAPBR was placed in a fully closed compartment with controlled temperature $\left(25^{\circ} \mathrm{C}\right)$. Illumination was provided by 8 fluorescent lamps (Sylvania Standard $36 \mathrm{FW}$ ) all placed at the same distance from the SCAPBR surface $(200 \mathrm{~mm})$ and equidistant to each other $(60 \mathrm{~mm})$ on one side of the SCAPBR.

A photosynthetic photon flux density (PPFD) of $250 \mu \mathrm{mol} \mathrm{m}{ }^{-2} \mathrm{~s}^{-1}$ was used, as determined (in triplicate) behind the front surface of the SCAPBR at 5 different points in the absence of the microalgal culture, by averaging the values of light intensities measured with a LI-COR Quantum/Radiometer/Photometer Model LI-250 Light Meter (San Diego, CA, USA).

The light radiating from the central baffle to the interior of the SCAPBR was also measured. The SCAPBR was filled with water and externally covered with opaque paper except in the line that represents the intersection of the central baffle with the SCAPBR column, allowing the penetration of light there. The light flux conveyed by the central baffle was measured to be ca. $25 \mu \mathrm{mol} \mathrm{m}{ }^{-2} \mathrm{~s}^{-1}$ (at the baffle surface). This value is the average of the measurements (in triplicate) in 5 different points of the baffle and is independent of cell concentration, since the baffle is filled with water.

The quantitative and qualitative light characterization allows an extensive mapping of light regime in virtually all the SCAPBR volume at different cell concentrations. Therefore, the output of this light regime characterization will be the light intensity (in absolute value or per wavelength) in each point of the PBR through a 3D coordinates system. This data can be visualized if needed (Figs. 3 and 4) using appropriate software (e.g. Excel or OriginLab) or simply combined with flow pattern determination data in order to obtain the CLH.

\subsubsection{Quantitative light characterization}

Quantitative characterization of light regime was performed, as previously described [1], using a fibre optic spectrometer AvaSpec2048-4-DT (2048 pixel, $200-1100 \mathrm{~nm}$ ) coupled with a standard transmission probe, model T300-RT-VIS/NIR, controlled by AvaSoft 6.0 software. Data were acquired between 200 and $1100 \mathrm{~nm}$, but only the range between 400 and $700 \mathrm{~nm}$ (Photosynthetically Active Radiation PAR) was used for calculations.

In this case, quantification of the light penetrating in the culture was performed at different cell concentrations (ranging from 0.10 to 


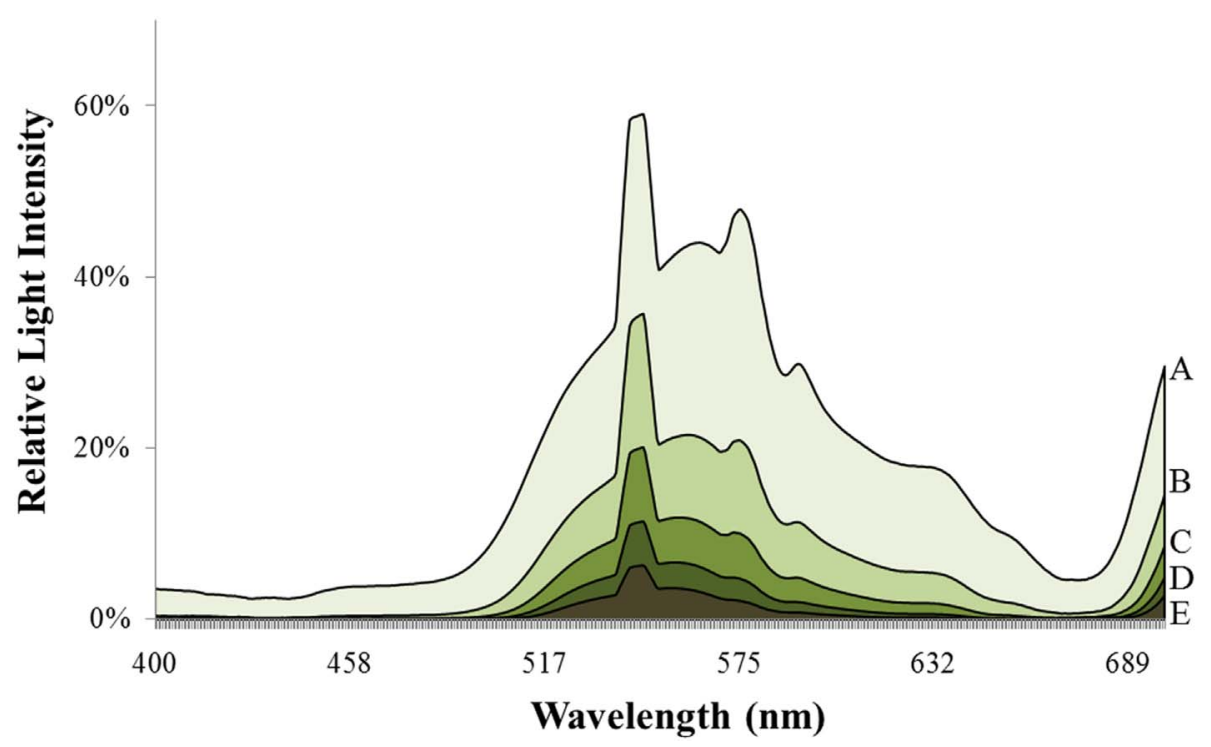

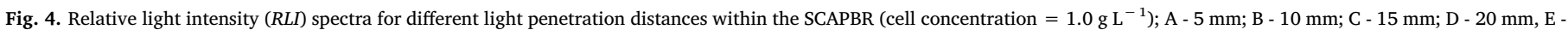
$25 \mathrm{~mm}$;

$1 \mathrm{~g} \mathrm{~L}^{-1}$ ), different radial positions and light penetration distances with $5 \mathrm{~mm}$ intervals (Fig. 2). All measurements were made in triplicate, and in all experiments the standard deviation was below $5 \%$.

As example, Fig. 3 shows the light intensity (L.I.) variation profiles at two of the different concentrations tested $\left(0.25 \mathrm{~g} \mathrm{~L}^{-1}\right.$ and $1.0 \mathrm{~g} \mathrm{~L}^{-1}$ ). For visualization purposes the graphical representation of quantitative light characterization data was performed using OriginLab 6.1 software. However, if the purpose is just to determine the CLH, graphical representation is not required. The maximum cell concentration used for graphic purposes was $1.0 \mathrm{~g} \mathrm{~L}^{-1}$ because above that value no changes in the light profile were observed inside the $5 \mathrm{~mm}$ scale used (data not shown).

Through Fig. 3, it is possible to see that at cell concentrations higher than $1.0 \mathrm{~g} \mathrm{~L}^{-1}$, the cells only have access to light when they circulate along the SCAPBR walls and along both sides of the central baffle wall. Despite these results about light intensity profiles inside the PBRs provide very useful information, it is not possible to use its full potential while cells' flow pattern is not known.

\subsubsection{Qualitative light characterization}

There is no need for additional assays to obtain qualitative data, since the procedure previously described for quantitative data also supplies the qualitative information [1]. The same equipment and software were thus used.

The "quality" (wavelength) of light penetrating into the culture is expressed through the relative light intensity (RLI), which is the ratio of the light intensity $(L I)$, at each wavelength, measured at a given point in the SCAPBR (at different cell concentrations, different radial positions, and light penetration distances) and the reference light intensity $\left(L I_{R}\right)$, which is measured at the same wavelengths inside the vessel filled with medium in the absence of cells (Eq. (1)).

$\mathrm{RLI}=L I / L I_{R} * 100$

All measurements are made in triplicate and in all experiments the standard deviation was below $5 \%$.

Fig. 4 shows an example of the information that can be obtained with this technique, i.e. the qualitative light characterization in the SCAPBR filled with Chlorella vulgaris $\left(1.0 \mathrm{~g} \mathrm{~L}^{-1}\right)$ at different light penetration distances. As for the quantitative light characterization, there is no need for graphical representation if the objective is just to obtain the CLH, since the information that will be used is the intensity of each wavelength in each of the PBR's 3D coordinates.

\subsection{Particle tracking technique}

The flow pattern visualization technique is based on tracking one neutrally buoyant and fully wet alginate $(0.5 \% \mathrm{w} / \mathrm{v})$ sphere having a mean size of $4.0 \mathrm{~mm}$ and containing riboflavin (R4500, Sigma-Aldrich) at $0.001 \% \mathrm{w} / \mathrm{v}$. This particle had a relative density of 0.998 (using water at $25{ }^{\circ} \mathrm{C}$ as reference).

The utilization of such particle enables establishing a versatile (and cheap) flow pattern visualization technique because it is very easy to produce alginate particles with different sizes and densities allowing to characterize the flow patterns of liquids or denser particles like cell flocs [40].

The alginate particle is placed in the liquid phase and illuminated at 90 degrees by two fluorescent black lights (F20T9/BLB) in order to make the incorporated riboflavin glow.

Particle flow was followed by recording sets of images with 2 perpendicular cameras (Canon EOS 600D - frame rate of 50 images/s) placed around the SCAPBR and connected to a PC. The two cameras were adjusted to the desired height and distance from the SCAPBR (approx. $50 \mathrm{~cm}$ ) so that cameras cover the entire reactor. The data obtained (images) were stored in the computer.

The film was processed using Premiere Pro CS5 (Adobe Systems Incorporated) and divided in a sequence of at least 12,000 image snapshots (see examples of black and white frames in Fig. 5). Such experiments were implemented using an air-water system at two different values of gas superficial velocity $\left(U_{G r}\right)-0.44 \mathrm{~cm} \cdot \mathrm{s}^{-1}$ and $0.77 \mathrm{~cm} \cdot \mathrm{s}^{-1}$ - which is directly related to the liquid circulation velocity in the reactor. The particle movement inside the SCAPBR was recorded until at least 100 trajectories were captured.

\subsubsection{Flow pattern visualization}

The particle tracking technique described above allows recording the trajectory of a buoyant particle which movement simulates the main trajectories of the microalgae cells inside a PBR.

Knowing how the cells move in and out of illuminated zones of the PBR allows understanding and optimizing PBR productivity [31]. In that sense, the existence of a technique that could give a fast and accurate visualization about the flow pattern inside the PBR can be very useful for optimization purposes. For example, if the objective is to maintain a well-defined and repetitive flow pattern inside an airlift bioreactor, the operator can set the initial operational parameters (e.g. aeration rate or baffle position) and after $3-5 \mathrm{~min}$ a descriptive 

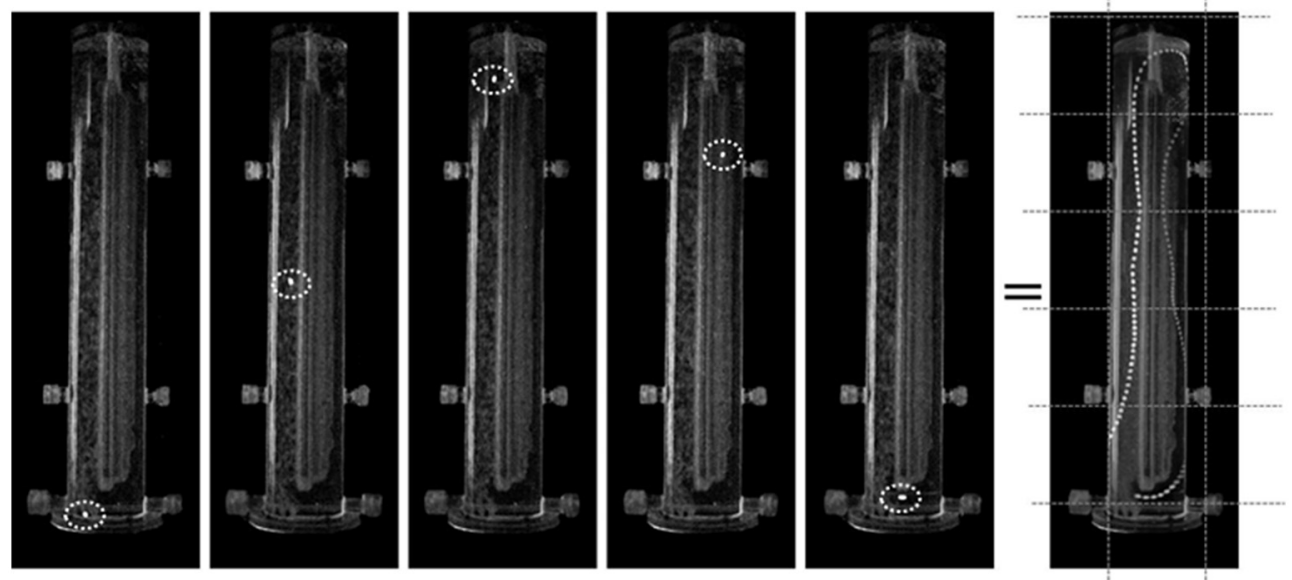

$t_{0}+(\ldots)$

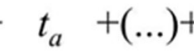

$t_{b}+(\ldots)+$

$t_{c}+(\ldots)+t_{f}$

$=\Delta t_{L A P}$

Fig. 5. Image overlapping of sequential frames $\left(t_{0}-t_{\text {final }}\right)$ in order to obtain a complete trajectory.

representation of the flow pattern inside the bioreactor will be presented. Depending on the results, the operator can change the operational parameters and repeat the process.

Fig. 4 shows different frames in which the alginate particle is visible in a plane parallel to the light source (used for growth), i.e. a plane perpendicular to the central wall of SCAPBR (riser is on the left side and downcomer on the right side of each individual SCAPBR image).

The flow pattern visualization (Fig. 6) can be achieved by overlapping all the frames (obtained during the footage). The frame overlapping was done using the Startrail application (Startrails ${ }^{(\mathrm{C})} \mathrm{v}$ 2.3, Achim Schaller, 2013) in order to obtain a clear image of the trajectory made by the particle inside the SCAPBR.

Flow visualization studies such as those shown in the right image of Fig. 5 and in Fig. 6 provide a useful insight into PBRs circulation patterns, identification of dead zones and regions of intense turbulence. Moreover, by a primary data treatment (cf. 2.2.2) it is possible to obtain other liquid-phase properties such as: liquid velocity and circulation time. Finally, it is possible to combine the results of two or more rounds (Fig. 6) and have a clear idea of the main trajectories from the alginate particle.

As an example, the flow pattern inside the SCAPBR operating at two different values of gas superficial velocity $\left(U_{G r}\right)-0.44 \mathrm{~cm} \cdot \mathrm{s}^{-1}$ and $0.77 \mathrm{~cm} \cdot \mathrm{s}^{-1}-$ are presented (Fig. 6).

Black and white pictures are shown because this will facilitate further image processing (cf. Section 2.2.2). Though, for results interpretation purposes it is easier if each of the particles' complete

$0.44 \mathrm{~cm}^{-1}$

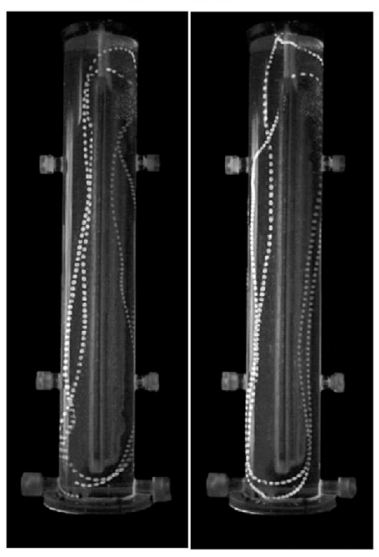

Fig. 6. Alginate particle trajectories (2 per picture) at two different gas superficial velocities $\left(0.44 \mathrm{~cm} \cdot \mathrm{s}^{-1}\right.$ and $\left.0.77 \mathrm{~cm} \cdot \mathrm{s}^{-1}\right)$ inside the SCAPBR. circulation trajectories in the reactor are marked with different colours, which can be done automatically through software such as Adobe Photoshop CS5. Also, in each of the pictures presented in Fig. 6, only 2 trajectories ( 1 trajectory represent 1 particle circulation, which means that the time needed for 1 trajectory can be regarded as circulation time) are shown. This was done only for visualization purposes, since we can add as many trajectories as we want using this technique.

With just a visual analysis of these images (without the further analysis that will be presented in the following sections) it is possible to i) take conclusions regarding the chaotic or well-defined flow pattern that the particle is following; ii) identify dead zones inside the reactor; iii) observe if particles alternate between theoretical light and dark regions of the reactor or if they get trapped in a particular region. All these observations can be quickly and easily re-evaluated after some changes in operational parameters or reactor design enabling conclusions on how those changes can affect those observations. Therefore, this is a low-cost, fast and intuitive technique that can be used during PBR design and optimization to visualize the flow pattern. However, to get quantitative information from these results the images need to be processed (cf. Section 2.2.2).

\subsubsection{Primary image data treatment - particle detection and data extraction from the videos}

In order to automatically and accurately obtain data regarding the particle's flow pattern and velocity, the frames obtained from the videos (cf. 2.2.1) were processed and analysed using an in-house built MATLAB algorithm. This technique consisted in the detection and parameterization of all the objects in each frame based on combinations of size and grey-scale intensity. Considering the differences in brightness, shape and size of the alginate particle when compared to the air bubbles inside the SCAPBR, an approach similar to the two-parameter phase discrimination [41] was selected as the most suitable and the particle was easily identified in each frame (Fig. 7).

In order to enable the detection of the alginate particle, the first step of the algorithm was to make the image background as uniform as possible since the original image background presented variable levels of darkness. The image contrast was then increased to maximize the particle detection followed by an image binarization into black and white form (Fig. 7) via thresholding. Consequently, it was possible to apply a "bwlabel" function to identify all the objects in the image. As the particle dimensions are known it was possible to isolate the bubble from particles and by previous calibration obtain its position in the plane. Therefore, properties such as: particle position in 3D coordinates, average intensity and area were obtained from the binary images of all video frames. With the intention of implementing a methodology to 


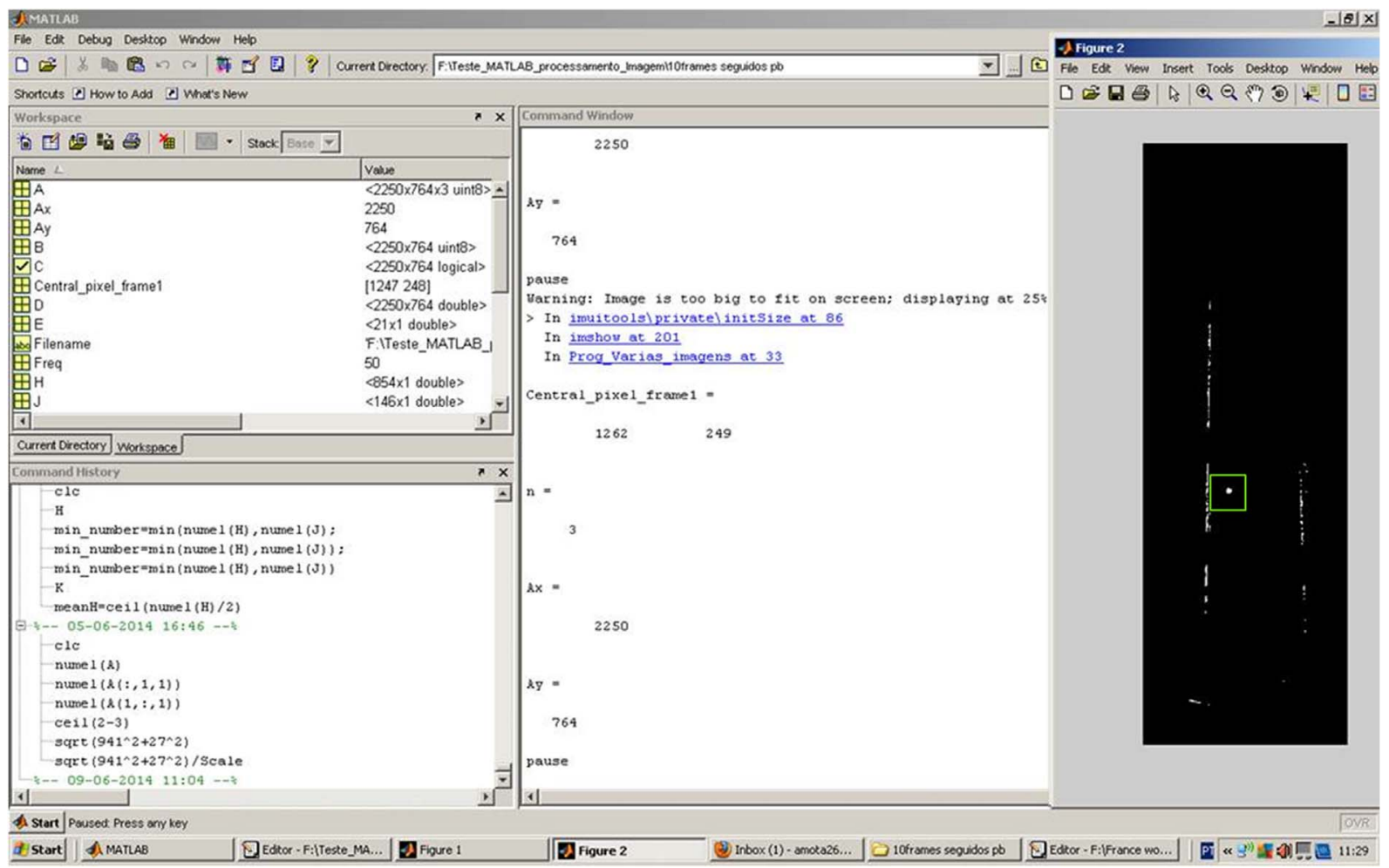

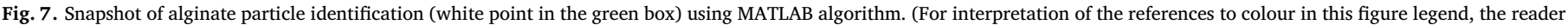
is referred to the web version of this article.)

determine the 3D coordinates and relate them with each camera pixel, reference points were set in the SCAPBR before flow pattern tests were performed.

\subsection{Merging and synchronization of light regime and flow pattern data}

As result of the steps described in Sections 2.1 and 2.2 a complete mapping of the SCAPBR was obtained regarding light distribution and particle position. This means that information associated with light regime and particle position can be attributed to each SCAPBR's 3D coordinate $(x, y, z)$. However, these two independent groups of data need to be merged and synchronized in order to obtain the CLH (Fig. 8).

Since the 2 cameras work simultaneously, the centre particle height ( $z$ coordinate) and time are used as common values to obtain the $x$ and $y$ coordinates of the particle. This means that it is relatively simple to obtain the location in 3D coordinates. Moreover once two coordinates from each camera ( $z$ and time) are used to define the 3D position, errors can be detected easily and removed for statistical analysis, which increases the system's robustness.

After knowing the global particle position over time, it is easy to calculate velocity and the average time each particle spends in each light regime area, allowing to finally obtain the CLH.

\section{Technique output and potentialities}

This technique was specially developed to assist in the design, characterization and optimization of photobioreactors for the cultivation of photosynthetic microorganisms. The procedure consists in merging and synchronization of data from two different techniques that can be used separately for: 1) characterizing the light regime; 2) characterizing and visualizing the flow pattern. However, the combined use of these techniques boosts their individual potentialities by enabling the determination of the CLH inside the PBR. This is of extreme importance since no affordable, accurate and user-friendly solution for CLH is currently available.
The very simple MATLAB algorithm developed allows not only to synchronize data from both techniques, but also to make very simple calculations that enable us to obtain: $i$ ) a report with the time, particle position (coordinates) and light intensity in each frame (Fig. 9); and ii) a report with CLH and some basic hydrodynamic parameters (Fig. 10).

The results (outputs) presented in Fig. 10 were obtained by averaging 100 circulations in the SCAPBR at a gas superficial velocity $\left(U_{G r}\right)$ of $0.44 \mathrm{~cm} \cdot \mathrm{s}^{-1}$ and a cell concentration of $0.25 \mathrm{~g} \mathrm{~L}^{-1}$.

Outputs such as $i$ ) the fraction of time that the particle spends in each light regime (CLH); ii) the average irradiance that the particle experienced (CLH); iii) the average $L / D$ frequency - the frequency at which cells change from "light" conditions to "dark" conditions can be easily determined by defining a "light" and a "dark" threshold and then calculating the time that the particle takes to pass from a "light" condition to a "dark" condition; $i v$ ) the circulation time - time between successive passages of the alginate particle by a reference line; $v$ ) the velocity in the downcomer and in the riser - time that the particle takes to pass through each section (i.e. downcomer and riser) divided by its length; vi) the gas holdup - it is obtained by measuring the difference between the height of the surface of the liquid under aerated conditions and its height under non-aerated conditions.

\section{Conclusions}

This paper presents the development of a novel user-friendly platform to couple light regime characterization with particle tracking in order to determine cells' light history during phototrophic cultivations.

The technique merges and synchronizes, by means of an in-house developed MATLAB algorithm, the data from light characterization (obtained using fibre optic technology) and flow pattern determination (obtained by particle tracking). Through the algorithm, each 3D position of the PBR is characterized both in terms of light and presence/absence of the fluorescent tracer particle. This novel technique has been successfully applied in a SCAPBR 50 used to cultivate $C$. 


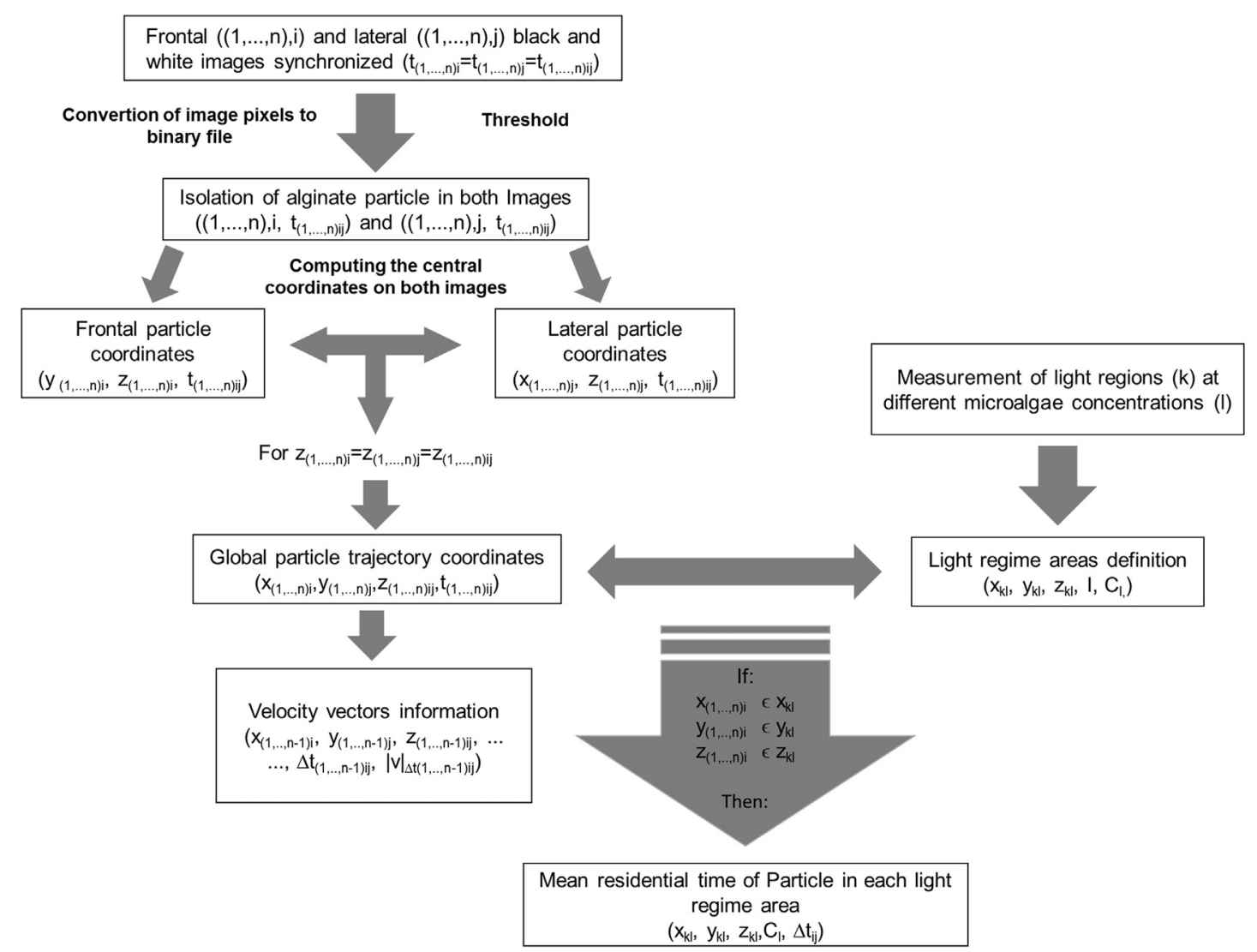

Fig. 8. Schematic representation of data merging and synchronization for CLH determination.

\begin{tabular}{|c|c|c|c|}
\hline Time ${ }_{0}(\mathrm{~ms})$ & $\begin{array}{c}\text { Particle coordinates } \\
{\left[\begin{array}{ccc}11 & 2 & 5\end{array}\right]}\end{array}$ & $(x, y, z)$ & I I $\frac{(\mu \mathrm{mol} . \mathrm{m}-2 . \mathrm{s}-1)}{85}$ \\
\hline 20 & {$\left[\begin{array}{llll}10 & 2 & 7\end{array}\right]$} & & 85 \\
\hline 40 & {$\left[\begin{array}{llll}11 & 1 & 8\end{array}\right]$} & & 85 \\
\hline 60 & {$\left[\begin{array}{lllll}10 & 1 & 8\end{array}\right]$} & & 84 \\
\hline 80 & {$\left[\begin{array}{llll}12 & 3 & 10\end{array}\right]$} & & 85 \\
\hline 100 & {$\left[\begin{array}{llll}13 & 5 & 11\end{array}\right]$} & & 84 \\
\hline 120 & {$\left[\begin{array}{llll}10 & 8 & 12\end{array}\right]$} & & 83 \\
\hline 140 & {$\left[\begin{array}{llll}10 & 6 & 14\end{array}\right]$} & & 85 \\
\hline 160 & {$\left[\begin{array}{llll}11 & 6 & 14\end{array}\right]$} & & 85 \\
\hline 180 & {$\left[\begin{array}{llll}11 & 8 & 16\end{array}\right]$} & & 83 \\
\hline 200 & {$\left[\begin{array}{llll}11 & 6 & 18\end{array}\right]$} & & 85 \\
\hline 220 & {$\left[\begin{array}{llll}10 & 9 & 21\end{array}\right]$} & & 84 \\
\hline 240 & [ $\left.\begin{array}{llll}12 & 8 & 22\end{array}\right]$ & & 84 \\
\hline 260 & {$\left[\begin{array}{lll}12 & 10 & 25\end{array}\right]$} & & 84 \\
\hline 280 & {$\left[\begin{array}{llll}14 & 11 & 24\end{array}\right]$} & & 85 \\
\hline 300 & {$\left[\begin{array}{lll}11 & 12 & 25\end{array}\right]$} & ] & 83 \\
\hline 320 & {$\left[\begin{array}{lll}11 & 12 & 26\end{array}\right]$} & & 85 \\
\hline$\cdots$ & $\cdots$ & & $\cdots$ \\
\hline
\end{tabular}

Fig. 9. Sample of results for particle position and respective light intensity in each frame.

vulgaris.

Illustrative results obtained during the implementation of this new technique have been presented in order to describe the concept and prove that it is suitable for the determination of CLH in PBRs providing a direct and comprehensive tool for the design, characterization and optimization of PBRs.

\section{Acknowledgements}

This research work was supported by the grant SFRH/BPD/98694/ 2013 (Bruno Fernandes) and SFRH/BD/52335/2013 (Pedro Geada) from Fundação para a Ciência e a Tecnologia (Portugal). This study was supported by the Portuguese Foundation for Science and Technology (FCT) under the scope of the strategic funding of UID/BIO/04469/2013 unit and COMPETE 2020 (POCI-01-0145-FEDER-006684), Project RECI/BBB-EBI/0179/2012 (FCOMP-01-0124-FEDER-027462) and FCT Strategic Project of UID/BIO/04469/2013 and UID/Multi/04423/2013

$\begin{array}{cc}\text { LI }(\mu \mathrm{mol} . \mathrm{m}-2 . \mathrm{s}-1) & \text { Fraction of time in each LI (\%) } \\ 0-5 & 15 \\ 5-25 & 22 \\ 25-50 & 17 \\ 50-75 & 15 \\ 75-100 & 8 \\ 100-125 & 5 \\ 125-150 & 5 \\ 150-175 & 5 \\ 175-200 & 3 \\ 200-225 & 3 \\ 225-250 & 2 \\ ------------------------------- & \\ & 63.8 \\ \text { Average LI ( } \mu \text { mol.m-2.s-1) } & 2.6 \\ \text { Average L/D frequency (s-1) } & 9.7 \\ \text { Circulation time (s) } & 0.11 \\ \text { V downcomer (m.s-1) } & 0.15 \\ \text { V riser (m.s-1) } & 1.2 \\ \text { Gas holdup (\%) }\end{array}$

Fig. 10. Snapshot of the output values.

unit and COMPETE 2020 (POCI-01-0145-FEDER-006684) and BioTecNorte operation (NORTE-01-0145-FEDER-000004) funded by European Regional Development Fund under the scope of Norte2020 - Programa Operacional Regional do Norte.

\section{References}

[1] B.D. Fernandes, G. Dragone, J.A. Teixeira, A.A. Vicente, Light Regime Characterization in an Airlift Photobioreactor for Production of Microalgae With High Starch Content, 161 (2010), pp. 218-226.

[2] B.D. Fernandes, A. Mota, A. Ferreira, G. Dragone, J.A. Teixeira, A.A. Vicente, Characterization of split cylinder airlift photobioreactors for efficient microalgae cultivation, Chem. Eng. Sci. 117 (2014) 445-454. 
[3] J.C. Merchuk, M. Ronen, S. Giris, S. Arad, Light/dark cycles in the growth of the red microalga Porphyridium sp, Biotechnol. Bioeng. 59 (1998) 705-713.

[4] X. Wu, J.C. Merchuk, A model integrating fluid dynamics in photosynthesis and photoinhibition processes, Chem. Eng. Sci. 56 (2001) 3527-3538.

[5] Y.K. Lee, S.J. Pirt, Energetics of photosynthetic algal growth: influence of intermittent illumination in short (40 s) cycles, J. Gen. Microbiol. 124 (1981) 43-52.

[6] J. Degen, A. Uebele, A. Retze, U. Schmid-Staiger, W. Trösch, A novel airlift photobioreactor with baffles for improved light utilization through the flashing light effect, J. Biotechnol. 92 (2001) 89-94.

[7] X. Wu, J.C. Merchuk, Simulation of algae growth in a bench scale internal loop airlift reactor, Chem. Eng. Sci. 59 (2004) 2899-2912.

[8] M. Janssen, T.C. Kuijpers, B. Veldhoen, M.B. Ternbach, J. Tramper, L.R. Mur, R.H. Wijffels, Specific growth rate of Chlamydomonas reinhardtii and Chlorelle sorokiniana under medium duration light/dark cycles: 13-87 s, J. Biotechnol. 70 (1999) 323-333.

[9] E.A. Laws, K.L. Terry, J. Wickman, M.S. Chalup, A simple algal production system designed to utilize the flashing light effect, Biotechnol. Bioeng. 25 (1983) 2319-2335.

[10] K.L. Terry, Photosynthesis in modulated light: quantitative dependence of photosynthetic enhancement on flashing rate, Biotechnol. Bioeng. 28 (1986) 988-995.

[11] A. Richmond, Z. Cheng-Wu, Y. Zarmi, Efficient use of strong light for high photosynthetic productivity: interrelationships between the optical path, the optimal population density and cell-growth inhibition, Biomol. Eng. 20 (2003) 229-236.

[12] J.-F. Cornet, C.-G. Dussap, J.-B. Gros, Kinetics and energetics of photosynthetic micro-organisms in photobioreactors: application to spirulina growth, Adv. Biochem. Eng. Biotechnol. 59 (1998) 155-224.

[13] Z. Csogor, M. Herrenbauer, K. Schmidt, C. Posten, Light distribution in a novel photobioreactor - modelling for optimization, J. Appl. Phycol. 13 (2001) 325-333.

[14] F.G.A. Fernández, F.G. Camacho, J.A.S. Pérez, J.M.F. Sevilla, E.M. Grima, A model for light distribution and average solar irradiance inside outdoor tubular photobioreactors for the microalgal mass culture, Biotechnol. Bioeng. 55 (1997) 701-714.

[15] I.S. Suh, S.B. Lee, A light distribution model for an internally radiating photobioreactor, Biotechnol. Bioeng. 82 (2003) 180-189.

[16] M.R. Tredici, G.C. Zitelli, Efficiency of sunlight utilization: tubular versus flat photobioreactors, Biotechnol. Bioeng. 57 (1998) 187-197.

[17] Y.-S. Yun, J.M. Park, Kinetic modeling of the light-dependent photosynthetic activity of the green microalga Chlorella vulgaris, Biotechnol. Bioeng. 83 (2003) 303-311.

[18] L. Pottier, J. Pruvost, J. Deremetz, J.F. Cornet, J. Legrand, C.G. Dussap, A fully predictive model for one-dimensional light attenuation by Chlamydomonas reinhardtii in a torus photobioreactor, Biotechnol. Bioeng. 91 (2005) 569-582.

[19] J.F. Cornet, C.G. Dussap, J.B. Gros, C. Binois, C. Lasseur, A simplified monodimensional approach for modeling coupling between radiant light transfer and growth kinetics in photobioreactors, Chem. Eng. Sci. 50 (1995) 1489-1500.

[20] K. Loubière, E. Olivo, G. Bougaran, J. Pruvost, R. Robert, J. Legrand, A new photobioreactor for continuous microalgal production in hatcheries based on external-loop airlift and swirling flow, Biotechnol. Bioeng. 102 (2009) 132-147.

[21] J. Pruvost, J.F. Cornet, J. Legrand, Hydrodynamics influence on light conversion in photobioreactors: an energetically consistent analysis, Chem. Eng. Sci. 63 (2008) 3679-3694.

[22] J.-F. Cornet, J. Albiol, Modeling photoheterotrophic growth kinetics of Rhodospirillum rubrum in rectangular photobioreactors, Biotechnol. Prog. 16 (2000) 199-207.

[23] S. Hoekema, M. Bijmans, M. Janssen, J. Tramper, R.H. Wijffels, A pneumatically agitated flat-panel photobioreactor with gas re-circulation: anaerobic photoheterotrophic cultivation of a purple non-sulfur bacterium, Int. J. Hydrog. Energy 27 (2002) 1331-1338.

[24] A. Muller-Feuga, R. Le Guédes, J. Pruvost, Benefits and limitations of modeling for optimization of Porphyridium cruentum cultures in an annular photobioreactor, J. Biotechnol. 103 (2003) 153-163.

[25] J.C. Ogbonna, H. Yada, H. Masui, H. Tanaka, A novel internally illuminated stirred tank photobioreactor for large-scale cultivation of photosynthetic cells, J. Ferment. Bioeng. 82 (1996) 61-67.

[26] C.G.C. Zitelli, R. Pastorelli, M.R. Tredici, A modular flat panel photobioreactor (MFPP) for indoor mass cultivation of Nannochloropsis sp. under artificial illumination, J. Appl. Phycol. 12 (2000) 521-526.

[27] J. Pruvost, L. Pottier, J. Legrand, Numerical investigation of hydrodynamic and mixing conditions in a torus photobioreactor, Chem. Eng. Sci. 61 (2006) 4476-4489.

[28] Y.A. Hassan, T.K. Blanchat, C.H. Seeley Jr., R.E. Canaan, Simultaneous velocity measurements of both components of a two-phase flow using particle image velocimetry, Int. J. Multiphase Flow 18 (1992) 371-395.

[29] F. Larachi, J. Chaouki, G. Kennedy, M.P. Dudukovic, Chapter 11 - radioactive particle tracking in multiphase reactors: principles and applications, in: J. Chaouki, F. Larachi, M.P. Duduković (Eds.), Non-Invasive Monitoring of Multiphase Flows, Elsevier Science B.V, Amsterdam, 1997, pp. 335-406.

[30] H.-P. Luo, M.H. Al-Dahhan, Analyzing and modeling of photobioreactors by combining first principles of physiology and hydrodynamics, Biotechnol. Bioeng. 85 (2004) 382-393.

[31] H.-P. Luo, A. Kemoun, M.H. Al-Dahhan, J.M.F. Sevilla, J.L.G.a. Sánchez, F.G.a. Camacho, E.M. Grima, Analysis of photobioreactors for culturing high-value microalgae and cyanobacteria via an advanced diagnostic technique: CARPT, Chem. Eng. Sci. 58 (2003) 2519-2527.

[32] A. Muller-Feuga, J. Pruvost, R. Le Guédes, L. Le Déan, P. Legentilhomme, J. Legrand, Swirling flow implementation in a photobioreactor for batch and continuous cultures of Porphyridium cruentum, Biotechnol. Bioeng. 84 (2003) 544-551.

[33] I. Perner-Nochta, C. Posten, Simulations of light intensity variation in photobioreactors, J. Biotechnol. 131 (2007) 276-285.

[34] J. Pruvost, J. Legrand, P. Legentilhomme, Numerical investigation of bend and torus flows, part I: effect of swirl motion on flow structure in U-bend, Chem. Eng. Sci. 59 (2004) 3345-3357.

[35] J. Pruvost, J. Legrand, P. Legentilhomme, A. Muller-Feuga, Simulation of microalgae growth in limiting light conditions: flow effect, AIChE J. 48 (2002) 1109-1120.

[36] J. Pruvost, J. Legrand, P. Legentilhomme, A. Muller-Feuga, Trajectory Lagrangian model for turbulent swirling flow in an annular cell comparison with RTD measurements, Chem. Eng. Sci. 57 (2002) 1205-1215.

[37] J. Pruvost, J. Legrand, P. Legentilhomme, J.M. Rosant, Numerical investigation of bend and torus flows-part II: flow simulation in torus reactor, Chem. Eng. Sci. 59 (2004) 3359-3370.

[38] R. Rosello Sastre, Z. Csögör, I. Perner-Nochta, P. Fleck-Schneider, C. Posten, Scaledown of microalgae cultivations in tubular photo-bioreactors-a conceptual approach, J. Biotechnol. 132 (2007) 127-133.

[39] L.B. Wu, Z. Li, Y.Z. Song, Hydrodynamic conditions in designed spiral photobioreactors, Bioresour. Technol. 101 (2010) 298-303.

[40] J. Klein, A.A. Vicente, J.A. Teixeira, Hydrodynamics of a three-phase airlift reactor with an enlarged separator - application to high cell density systems, Can. J. Chem. Eng. 81 (2003) 433-443.

[41] D.A. Khalitov, E.K. Longmire, Simultaneous two-phase PIV by two-parameter phase discrimination, Exp. Fluids 32 (2002) 252-268. 